\title{
Skin Temperature Changes to Strong Low Rate Acupuncture -Like TENS in Raynaud's Disease.
}

\author{
Z. Mowafy Emam Mowafy* and Akef A Khowailed** \\ * Physical Therapy Department for Surgery, Faculty of Physical Therapy, Cairo \\ University, Egypt. \\ ** Physiology Department Faculty of Medicine, Cairo University, Egypt.
}

\begin{abstract}
The purpose of this study was to determine the effect of the strong low rate(SLR) acupuncture -like TENS on the skin temperature in Raynaud's disease. Forty patients (30 females and 10 males) suffering from Raynaud's disease with no other systemic or metabolic disorders, participated in this study. Their age ranged from 20 to 40 years $(X=27.35 \pm 4.41)$. They were divided randomly into two groups of equal number and consented to receive SLR, Acupuncture-like TENS for the first study group and placebo TENS for the second control group, on the thoraco-lumber region from a dual-channel TENS unit. Assessment of the skin temperature from the big toe and little finger was carried out before and after treatment ( session for 20 minutes) at the same times on 3 consecutive days, in an air conditioned room, with the ambient room temperature was adjusted between $24^{\circ} \mathrm{C}$ to $28^{\circ} \mathrm{C}$. Before starting the treatment program results showed no significant difference in the toe skin temperature (TST), in ${ }^{\circ} \mathrm{C}$ between the study and control groups as it was $29.91 \pm 2.44$ and $28.7 \pm 1.23$ for the study and control groups respectively. Also no significant difference was recorded in the finger skin temperature (FST), as it was $28.85 \pm 2.36$ and $27.45 \pm 1.17$ for the study and control groups respectively. Data collected at the end of the treatment program showed that averages of the (TST) in ${ }^{\circ} \mathrm{C}$ were $31.44 \pm 2.57$ and $28.85 \pm 1.237$ in the study and control groups respectively. While averages of (FST) in $^{\circ} \mathrm{C}$ were $30.75 \pm 2.51$ and $27.66 \pm 1.186$ in the study and control groups respectively. Results showed a significant increase in TST and FST at the end of the treatment program in the experimental group only, which suggested that SLR acupuncture -like TENS could be fruitful in Raynaud's disease.
\end{abstract}

\section{Introduction}

Raynaud's disease is an idiopathic trophoneurosis that is characterized by paroxysmal spasm of the digital arterioles, producing pallor or cyanosis of fingers or toes with numbness and occasionally resulting in gangrene, ${ }^{3.7 .10}$.

It is a disease of young women described by a French physician called Raynaud, ${ }^{2.5 .13}$.

Spasm of the digital arterioles causes capillary flow to cease, so that fingers or toes go white and numb. As the spasm disappears there is a reactive hyperaemia, the color of fingers or toes changes from blue to red, they throb, and patient experiences pins and needles, ${ }^{11.14 .22}$.

In some patients as the disease advances, the spasm fails to relax completely and in the course of time actual necrosis of fingers or toes tips may develop, ${ }^{8.15 .26}$.

Electrical eels were known to the Ancient Egyptians and to Hippocrates, 
for the treatment of gout and headache, ${ }^{1.4 .6 .12}$.

William Gilbert was the first to classify and generalize the phenomenon of electricity and the efficacy of TENS as a modality in the treatment of pain which has now been well established, ${ }^{23.25 .30}$.

There is a strong indication that TENS influences the autonomic nervous system dramatically, and may affect changes of neurohumoral mechanisms within the central nervous system, but investigation and further research in this area is still needed, ${ }^{9.18 .20 .28}$.

\section{Material and methods}

\section{Subjects:-}

Forty patients (30 females, and 10 males) ranging in age from 20 to 40 years, selected from the out patient clinics of Kasr-El-Aini (Cairo University Hospitals). They were divided randomly into two groups of equal number. The first (study) group received low TENS and the second (control) group received placebo TENS. All patients received the same physiotherapeutical program and the same medical and nursing care.

\section{Instrumentation:-}

The treatment equipment was a dual channel TENS stimulator, model DH- 808, made by DAE HAN in Korea. The stimulation parameters and the principal characteristics of the low TENS were, $10 \mathrm{~Hz}$ for the frequency, $400 \mu \mathrm{sec}$ for the pulse width, $80 \mathrm{~mA}$ for the intensity (strong to the level of tolerance with rhythmic visible muscle contractions), ${ }^{16.19 .27}$.

The measuring equipment in this study was, an electronic thermometer (Badr Telecom) number 6728085, model ( RKIII) made in Japan.

\section{Procedure:-}

\section{Evaluation}

Recording the (TST) and the (FST), was conducted before and after the treatment program. The evaluation and treatment were conducted in an air conditioned room, where a thermometer was available to maintain the ambient room temperature between $24^{\circ} \mathrm{C}$ to $28^{\circ} \mathrm{C}$ by setting the thermostat of the air condition, ${ }^{17.24 .29}$.

\section{Treatment:-}

According to the aformentioned stimulation parameters and principal characteristics of the SLR, acupuncture -like TENS, the dual channel TENS stimulator was used to administer the SLR, acupuncture-like TENS via 4 self-adhesive electrodes, that were placed over the thoraco-lumber junction paravertebrally ( 2 electrodes over the thoraco lumber junction and the other two electrodes below the thoracolumber junction), with the patient sitting on a stool, ${ }^{5.10 .18}$.

\section{Data Analysis:-}

One session for 20 minutes daily, conducted at the same time on 3 consecutive days was administered via the TENS stimulator. The TST and FST were recorded before and after treatment program. The collected data were fed into a computer for statistical analysis, the descriptive statistics as mean, standard deviation, minimum and maximum, were calculated for each group. The $\mathrm{t}-$ Test was done to compare between the mean differences of the two groups and within each group. Alpha point of 0.05 was used as a level of significance, ${ }^{21}$.

\section{Results:-}

In the present study, the effect of the SLR acupuncture -like TENS on 
TST and FST in Raynaud's disease was investigated. As shown in table (1) and demonstrated in Figure (1), the mean values of the TST before treatment in the study group was $(29.91 \pm 2.44)^{\circ} \mathrm{C}$, while after treatment was $(31.44 \pm 2.57)^{\circ} \mathrm{C}$. These results revealed a significant increase in TST $(\mathrm{P}<0.05)$. Also the mean values of the FST in the experimental group before treatment was $(28.85 \pm 2.36)^{\circ} \mathrm{C}, \quad$ while after treatment was $(30.75 \pm 2.51)^{\circ} \mathrm{C}$. Also these results revealed a significant increase in the FST $(\mathrm{P}<0.05)$. But in the control group as shown in table (2), and demonstrated in figure(2), the mean values of the TST before treatment was $(28.7 \pm 1.230)^{\circ} \mathrm{C}$ while after treatment was $(28.85 \pm 1.237)^{\circ} \mathrm{C}$. These results revealed a non -significant increase in TST ( $\mathrm{P}>$.0.05). Also the mean values of the FST in the control group before treatment was $(27.45 \pm 1.17)^{\circ} \mathrm{C}$, while after treatment was $(27.66 \pm 1.18)^{\circ} \mathrm{C}$, also these results revealed a nonsignificant increase in the FST $(\mathrm{P}>0.05)$.

Table (1): Comparison of the mean values of TST, and FST in ${ }^{\circ} \mathrm{C}$ before and after treatment in the study group.

\begin{tabular}{|c|c|c|c|c|c|}
\hline & \multicolumn{2}{|c|}{$\begin{array}{c}\text { Before } \\
\text { Treatment }\end{array}$} & \multicolumn{2}{c|}{$\begin{array}{c}\text { After } \\
\text { Treatment }\end{array}$} & \multirow{2}{*}{$\begin{array}{c}\text { P. } \\
\text { Value }\end{array}$} \\
\cline { 2 - 5 } & $\mathrm{X}$ & SD & $\mathrm{X}$ & SD & \\
\hline TST & 29.91 & 2.44 & 31.44 & 2.57 & $<0.05$ \\
& & & & & \\
\hline FST & 28.85 & 2.36 & 30.75 & 2.51 & $<0.05$ \\
\hline
\end{tabular}

\section{$\square$ Before Treatment $\square$ After Treatment}

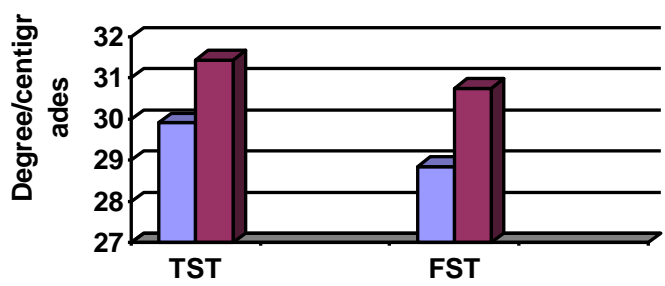

Evaluation Parameters

Fig. (1): mean values of TST and FST before and after treatment in the study group.

Table (2): Comparison of the mean values of TST, and FST in $\mathrm{C}^{\circ}$ before and after treatment in the control group.

\begin{tabular}{|c|c|c|c|c|c|}
\hline \multirow{2}{*}{} & \multicolumn{2}{|c|}{$\begin{array}{c}\text { Before } \\
\text { Treatment }\end{array}$} & \multicolumn{2}{c|}{$\begin{array}{c}\text { After } \\
\text { Treatment }\end{array}$} & \multirow{2}{*}{$\begin{array}{c}\text { P. } \\
\text { Value }\end{array}$} \\
\cline { 2 - 5 } & $\mathrm{X}$ & SD & $\mathrm{X}$ & SD & \\
\hline TST & 28.7 & 1.23 & 28.85 & 1.23 & $>0.05$ \\
\hline FST & 27.45 & 1.17 & 27.66 & 1.18 & $>0.05$ \\
\hline
\end{tabular}

QBeofre Treatment $\square$ After Treatment

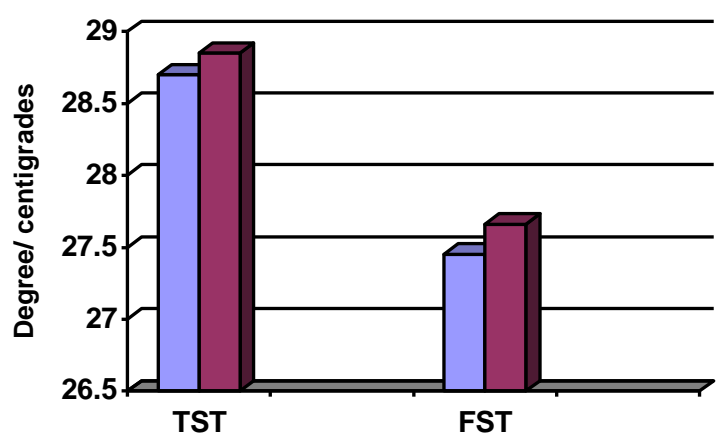

Evaluation Parameters

Fig.(2) : mean values of TST and FST before and after treatment in the control group.

\section{Discussion:-}

In the course of the nineteenth century, electrical and mechanical stimulation were employed as a therapy 
for many diseases by a large number of practising physicians. But in the twentieth century, with the increased number of efficient analgesics, turned interest away from peripheral stimulation as a pain relieving mode until Melzak and Wall(1965), published their gate control theory of pain, then conventional TENS was introduced as a test for the gate control theory of pain by WALL and Sweet in 1967, ${ }^{8.13 .19}$.

Raynaud's disease is a functional arterial disease caused by vasospasm, most often affecting arteries of fingers, characterized by an abnormality in the sympathetic nervous system, sensitivity to cold, blanching and cyanosis of the finger tips and nail beds, severe pain, sensory loss (tingling or numbness) and decreased hand function, ${ }^{15.26 .30 .}$.

The findings of the present study showed no significant difference in the pre-treatment records of the TST and FST, between the mean values of the first (study) and the second (control) groups. Results of control group were compared with each other and showed a non significant difference in both TST and FST before and after treatment $(\mathrm{P}>0.05)$. But results a of the experimental group revealed a significant increase in both TST and FST after the application of the SLR acupuncture -like TENS, where TST (2) compared with mean value of TST (1) as well as FST(2) compared with the mean value of FST (1), the significant increase in both TST and FST in the experimental group was consistent with those observed and recorded by Kaada et al, 1991; Rang and Dale ,1991; Skodler et al., 1987: Gersh and Wolf 1984, and Fischbach et al., 1979.

Results of this study supports the expectation that SLR, acupuncture Like-TENS was significantly effective in producing prolonged and widespread sympathetic inhibition resulting in improved skin micro-circulation, increased skin temperature, promoted tissue perfusion, decreased arterial level of catecholamines and decreased sympathetic tone.

\section{Conclusion:-}

The SLR, acupuncture -like TENS application was effective in increasing skin temperature via sympathetic inhibition, ameliorating the cutaneous blood flow and improving the Raynaud's phenomenon.

\section{References}

1. Abram, S. E, Asiddo, C. B. and Reynolds, A.C.: increased skin temperature during TENS. Anesth. Analg.Cleve.99:22,1980.

2. Admas ,R.D. and Victor, M.D. :principles of Neurology. Mc GrawHill, New York, PP1009-1077,1989.

3. Andersson,D.A. and Holmgren, E.: Analgesic effects of peripheral conditioning segmental mechanisms interacting with pain. Acupunct. Electrother. Res. 3:23, 1978.

4. Bjorna, H. and Kaada,B.: Successful treatment of itching and atopic eczema by TENS. Acupunct. Electrither. Res. 12 (2); 101-112. England, 1987.

5. Campbell,J.M. and Taub, A. : Local analgesia from percutaneous electrical stimulation. Arch. Neurol. 28 : 347, 1973.

6. Campbell J.M. Raja S.N. and Cohen, R.H.: peripheral neural mechanism of nocicption. Physiol. Rev.85:87$89,1989$.

7. Cheng,R.S. and Pomeranz, B.: Electroacupuncture analgesia could be mediated by at least two pain relieving mechanisms endorphin and nonendorphin systems. Life. Sci.26:631,1980.

8. Chun, SH. And Dikenson A.H.: pain ,enkphalin and Acupuncture, Nature, 283-344, 1980.

9. Christensen N.J. and GalboH.: Sympathetic nervous activity during 
exercise. Ann . Rev. Physiol., 45:139, 1983.

10. Cripps, D.J. :skin care and problems in the aged. Hosp.Pract. 12:119-127, 1977.

11. Donald D.E. and Shepherd J.T.: Autonomic regulation of the peripheral circulation. Ann. Rev. Physiol., 42:429,1980.

12. Dougherty R.J., : An alternative to drugs in the treatment of chronic pain AAFP, San Francisco Septeber2528,1978 .

13. Edwards F.R. and hirst G.D.S. :sympathetic neuro effector transmission in arteries and arterioles. Physiol. Rev., 69:546, 1989.

14. Emanuelsson H. Mannheimer C. and Waagstein F.., : Catecholamine metabolism during induced angina pectoris and the effect of TENS. Am. Heart. J.114(6):1360-6,1987.

15. Eriksson M.B. and Sjolund E.H.: Acupuncture like electroanalgesia in TENS resistant chronic pain in $\mathrm{Y}$ zotterman(ed): sensory function of the skin, pergamon press, Oxford,575581,1976 .

16. Fields H.L:Pain: New approaches to therapy . Ann. Neurol.9:101-106,1989.

17. Fields, H.L. and Basbaum, A.I.: Endogenous pain control system: Brain stem spinal pathways and endorphin circuity. Ann. Rev. neurosci.7:309$318,1989$.

18. Fischbach, G.D. Leeman S.E. and Mudge A. W.:TENS release enkephalin which inhibits the of substance "P" from sensory neurons. Proc nat. Acad. Sci U.S.A. 76:526530,1979.

19. Fischer M.V. Raab P. and Von R.J. : circulatory behaviour under electrostimulation Anaesthesia (E.S.A) anaesthesist, 32 (12) :591-596 West germany, 1983.

20. Francis G.S. and Cohn J.N. : catecholamines in cardio vascular diseases. Ann. Rev . Physiol., 45:270,1988.

21. Hubbard A.W. :Understanding statistics. Research methods. University of Illionis, 1982.

22. Kaada, B. : Vasodialtation induced by TENS in peripheral ischaemia (Raynaud's phenomenon and diabetic neuropathy) Eur. Heart. J. 3:3)3, 1982.

23. Kaada, B. Olsen E. and Eielsen, O.: TENS with Vasodilatation.Gen . Pharmacol.15(2) :107, 1984

24. Kaada, B., Flatheim , E. and Woie , L.: Low TENS in mild/ moderate hypertension, Clin. Physiol. 11(2):161168, 1991.

25. Kahn, J.: pain control with electrotherapy. PT.forum. 4:12,1985.

26. Kane, K. and Taub, A.: Ahistory of local electrical analgesia. Pain 1:125138, 1975.

27. Wilmore D.W., Watters J. and Bessey J. : Combined hormonal infusion stimulates the metabolic response to injury. Ann. Surg, 3:264$281,1984$.

28. Wolfe R.R. and Durkot M.J. :Evaluation of the role of the sympathetic nervous system in the response of subtrate kinetics and oxidation to burn injury. Circ. Shock,9:395-406, 1982.

29. Wolf S.L. : neurophysiological mechanisms in pain modulation: Relevance to TENS in Lampe:ClinicAL tens 3:49-51,1984.

30. Woolf C.J. and Wall P.D.: Endogenous opioid peptides and pain mechanisms: a complex relationship. Nature 306:739-740, 1983. 


\title{
تغيرات درجة حرارة الجلا الناتجة عن التنبية العصبى الكهربى ذو الترددات

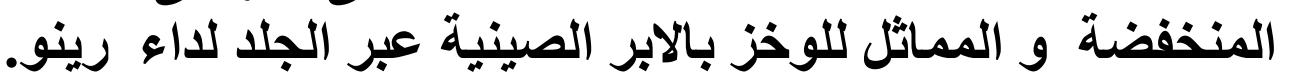

\author{
** زكريا موافى إمام موافى ، عاكف خويلا

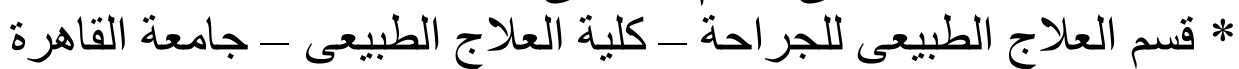

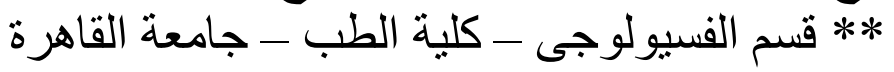

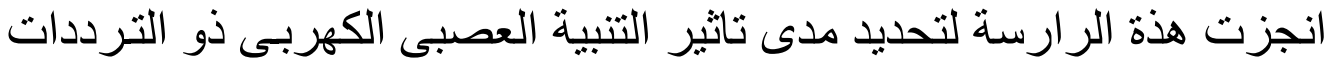

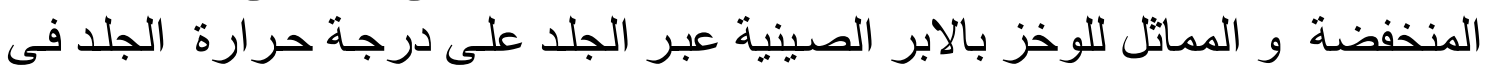

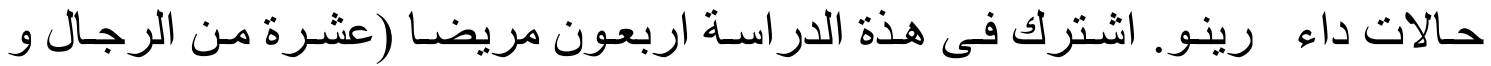

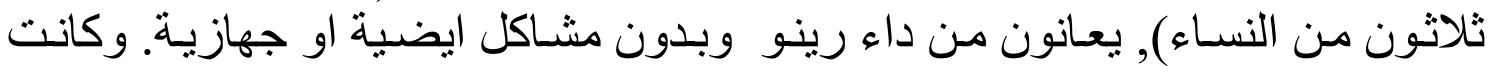

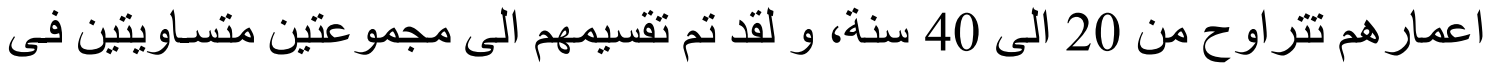

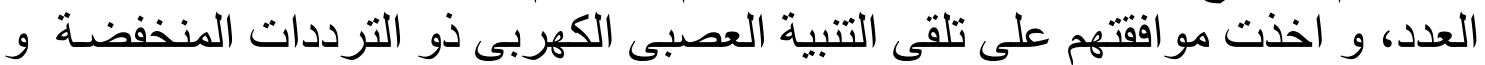

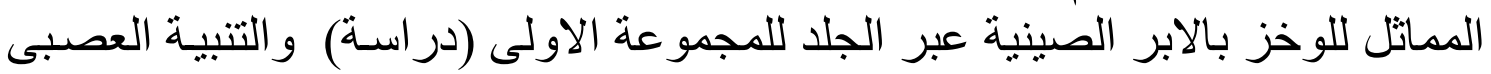

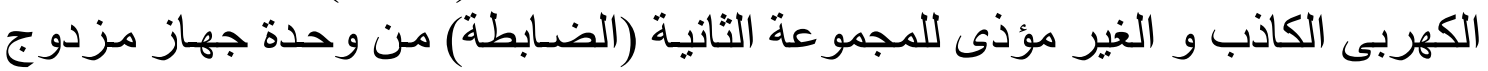

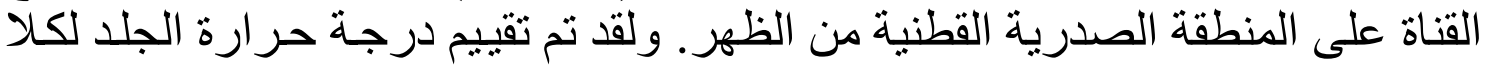

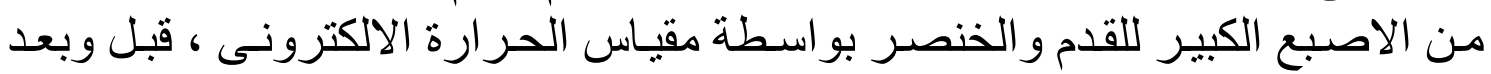

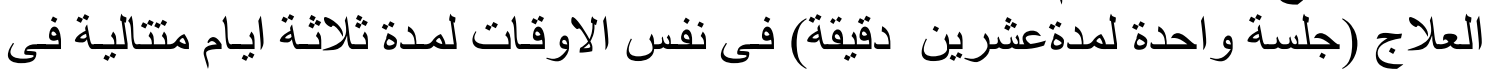

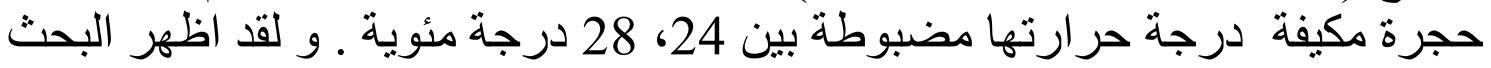

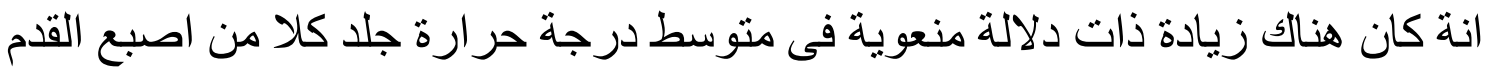

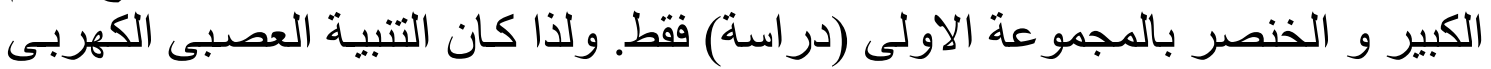

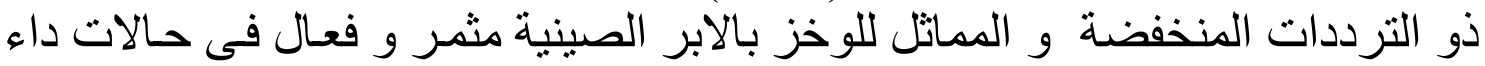

